\title{
New Problems and Solutions to Humanistic Management in Newly-built Colleges and Universities
}

\author{
Xinyu Li \\ Henan University of Animal, Husbandry and Economy, Zhengzhou, Henan, China
}

Keywords: New Problems, Solutions, Humanistic Management, Newly-built Colleges and Universities

\begin{abstract}
In recent years, a number of undergraduate colleges have emerged in the historic tide of modernization. They not only face good opportunities for development, but also face new problems in students' education management. In view of the grim situation that the new undergraduate college student education management faces now, the paper puts forward an effective way to solve the problem.
\end{abstract}

\section{Introduction}

With the deepening of the reform and development of higher education, in many aspects of the reform and development of higher education institutions, the organization of internal factors with human resources as the core, the regulation and control of the internal operation mechanism and the optimization of the internal governance structure have become the major factors influencing and restricting the establishment of higher education institutions Modern university system, an important factor to achieve the connotative development. At present, the internal management of most colleges and universities in our country still belongs to the typical "bureaucratic management" mode. "Bureaucratic" management promoted the development of colleges and universities under certain historical conditions. Within colleges and universities, a management system closely linked up and down and a clear division of labor was established. However, due to the hierarchical management system emphasizing hierarchy, concentration of powers, division of functions and strict compliance with established procedures, excessive emphasis on the institutionalized norms of behavior often results in neglect of human beings and inattentiveness of their subjectivity and innovation This has hindered the improvement of the running speed and organizational efficiency of the organization and has restricted the development of the university under the new historical conditions. The implementation of people-oriented management in colleges and universities is an important trend in the development of higher education. Modern education emphasizes respecting the essence of education and pursuing the liberation of human personality. It is required that modern university management fully reflects the respect and concern for human beings, emphasize the subjective role of human beings in various management tasks, and achieve the harmonious development of schools and teachers and students. And this idea is the essence of human-based management. Constructing a "people-oriented" management mode that conforms to the operating rules of colleges and universities and organically integrating human-based management with traditional bureaucracy and effectively improving the speed and efficiency of organizational operations and promoting the development of school education and human development have become the inevitable choice of modern colleges and universities.

\section{The Concept of College-Based Management}

With the progress of society and the constant improvement of employees' education, the relationship between the owner of an enterprise and the employee is no longer the relationship between employing and being employed, but also the relationship of the cooperator. Employees with high level of knowledge and skills become the most important resources and wealth of the enterprise, which determines the survival and development of the enterprise. Human-based 
management is born and developed in such a development. Human-based management thinking is human-centered human resources management thinking. It regards staffs as the most important resources of the enterprise, arranges appropriate jobs comprehensively with the knowledge level, basic skills and individual health conditions of the people, and fully considers the development of the employees and the individual needs, and uses scientific management methods, Through comprehensive human resource management, development and corporate culture construction, employees can fully mobilize and give full play to their enthusiasm, initiative and creativity in their work so as to enhance work efficiency and promote enterprise development. The most scientific way of modern enterprise management is human-based management. The core of management is people-oriented human-centered management. Enterprises respect the value of human beings in the production process and emphasize the subjective initiative of human beings and embody the human nature, dignity and value.

From a management point of view, people-oriented is based on the reality of the people, is a fundamental principle throughout the human world. Human-centered management centers on human nature, stimulates people's enthusiasm and creativity, and realizes the all-round development of man and the maximization of organizational benefits. In the contemporary era, people-oriented principles have increasingly become the principle commonly accepted in the management of the state and society at all levels. The task of colleges and universities is to cultivate talents, the implementation of education is the main body, educated people, people are the first element of university management. The management of colleges and universities should take people-oriented management as the core and mobilize the enthusiasm, creativity and learning consciousness of teachers and students through respect, support, encouragement and love, so as to create a harmonious and democratic campus atmosphere, so that the school management to educate people, develop people's process. This is the basic connotation of school-based management. From the relationship between managers and managers, the school-based management requires that managers in the management process, respect their values, personality and rights, and meet the needs of staff and students to achieve their self-worth. This management is characterized by the management of the integration of subject and object, leadership, teachers, students are the main body of management, their status is equal, independent personality, the three cross-communication and exchange, mutual promotion and common development. While respecting human values, we should establish a sound competition mechanism and form a positive and progressive driving force for development. From the perspective of the relationship between people inside the school, "people-centered" requires people to respect themselves, but also to respect others and work with colleagues, leaders and other working partners to establish a harmonious relationship of solidarity, mutual care and mutual assistance. Everyone has the right to develop themselves and realize their own values. At the same time, they must also respect the personality and rights of others. "Everyone can achieve his goal only as a means to others." Respect for others is a necessary condition for self-respect. Only Mutual respect can make people enjoy the dignity of personality.

\section{Problems and Reasons of Traditional Management in Colleges and Universities}

At present, the management level of higher education institutions is generally divided into three levels: high-level, middle-level and grassroots. The top is the decision-making level of colleges and universities, mainly school-level leadership, the smallest number; the middle is mainly the implementation of policy-making, is the administrative staff, slightly larger number of people; grassroots level is mainly the implementation of policy-making, mainly ordinary teachers and students, the largest number. In this way, colleges and universities formed a pyramid-shaped organizational structure. Teachers and students obey the arrangement of the director, while the dean leads the head of department, and the president and secretary take the overall situation of the school. The internal management of colleges and universities to establish a clear division of labor, closely linked to the management and operation of the system, the vertical management of the industry so that all departments within the university have relatively clear and specific responsibilities, responsibilities and division of labor within the University through various interconnected 
subsystems and networks to form a relatively stable, clear working procedures. Colleges and universities, colleges and departments constitute a top-down power system, maintaining the daily operation of colleges and universities.

In the bureaucratic structure, power gradually converges toward the top and bottom along the sides of the triangle, forming a vertically diverging power line like a pyramid. The number of people in the hierarchy is inversely proportional to the power. A handful of senior managers at the top of the triangle grasp the major decision-making powers in the organization. That is, the president (secretary) can quickly pass decisions through various levels to ensure work efficiency. . College administrators have a special division of labor at work, middle and grassroots personnel in the organization a large number of complex undertakings of specific tasks. The scope of business, working procedures, standards of conduct and duties of each department in the school system within the organization of each university department is clearly defined in the form of rules and regulations. Take the Student Affairs Office of the school as an example. The internal division is divided into Student Management Section, Ideological and Political Education Section, Student Subsidy Section and Dormitory Management Section. Different departments and departments have distinct division of labor and responsibilities, thus maintaining the normal operation of the organization.

Hierarchical organizational structure, organizational activities based on the members of the various rules and regulations, rather than personal will. "Bureaucratic" management has the characteristics of one-way. For school organizations, in the face of a stable, predictable and relatively homogeneous environment, bureaucrats are better choices to deal with routine and recurring events more efficiently. However, with the continuous deepening of reform in colleges and universities and the continuous advancement of modernization, people play an increasingly important role in the management system of colleges and universities. The interaction and promotion of human beings are becoming more and more active. The management of traditional bureaucracy in the management system the operating mechanism, the strict compliance with existing procedures and the system rules neglected by "human beings" become more and more rigid. As a result, the management efficiency of higher education institutions is low and the dynamics, stability and human subjectivity of the organization are affected.

\section{Construction and Implementation of Humanistic Management in Colleges and Universities}

Streamline the organization and improve efficiency. Simplifying the organizational structure and power structure of colleges and universities and improving work efficiency are the prerequisites for realizing humanistic management in colleges and universities. In their work, colleges and universities should further streamline the organizational structure, control the number of management teams, and effectively improve the management ability of working people. At the same time, in the management process, schools must simplify management procedures, reduce management links, open up green, convenient and smooth office access and facilitate teachers' teaching activities. At the same time, we should highlight the service functions in various management measures, implement humane and individualized services, and better mobilize the enthusiasm and creativity of teachers.

Reform the management system so as to shift the focus of management. College (Department) is a matrix composed of disciplines and institutions. In this matrix structure, teaching and research personnel are under double authority, belonging to one subject and one school at the same time. College (Department) is a collection of similar professional, is the basis of higher school management. Focusing management on the departments (departments) can give more play to the initiative of all grassroots units so that they can establish a self-regulating mechanism, strengthen coordination and exchange of information, better mobilize the enthusiasm of the general teaching and research staff and Initiative. At the same time, we must further transform our work functions and embody humanistic care in our service. University managers should change their concepts, reflect their sense of service in all aspects of practical management, and take care of teachers in all aspects and all-round development of students as the management aim of the school and do a good 
job in management.

Understand rely on teachers, first of all, is concerned with the progress of their thinking, to meet the spiritual needs of their ideological progress and development; followed by the work of caring for their satisfaction, there is no difficulty, and help solve practical problems, concerned about their business level and care about their career prospects Development and satisfaction of their continuing desire for education to meet their own self-development needs of self-development; the third is to care for their lives in the basic necessities of life, care about their physical and mental health and emotional, to meet their life and basic material needs, the formation of " Everyone is valued, everyone is respected, and everyone has development. "As a result, most teachers realize that they have self-esteem in their care, ownership in respect and self-actualization in their development. Real feelings to keep people, keep people, treatment stay.

To Establish a New View of Students, Strengthen Quality Education and Promote Students' All-round Development. Take inspiration, encouragement and guidance, respect, understand, care about them, to inspire and educate students, to mobilize the initiative of students' self-education. To all-round caring students, caring for the all-round development of students, caring for students 'physical and mental health, caring for students' personality development and caring for students 'reasonable needs, school management should proceed from students' physical and mental development to meet their reasonable needs.

Strengthening the self-construction and professional ethics building of the management team is an important aspect to realize the school-based management. School administrators should emphasize the awareness of service management, management awareness of educating people, change the traditional "authority" awareness, truly emancipate the mind become a public servant of the development of students and teachers. We must earnestly strengthen the work style of the leading bodies and serve the broad masses of teachers and students, thus forming a culture that takes pains and excuses and enjoys first and foremost, and takes the lead in setting examples. We should strengthen theoretical study, cultural study and business study so that school administrators should not only have managerial skills, but also have a certain degree of cultural accomplishment, advanced education theory and profound theoretical basis of politics. Only by strengthening the construction of professional ethics by schools and schools only a centripetal force, cohesion, charisma.

\section{Conclusions}

The development of management science theory and the practice of university management have a very important influence on the management of higher education. Human-based management has become an important trend of future education and management in colleges and universities. With the deepening of the reform and development of higher education, obsolete educational concepts, educational thoughts and systems in the traditional management of higher education have failed to meet the needs of the development of the times and the realization of personal values. To some extent, people-based management in colleges and universities has solved the problems that arise in the operation of the traditional management mode. It emphasizes the mutual development of managers and managers, the more flexible management mechanism, the more smooth management channels and the more efficient management high. It takes humanity as the ultimate concern, but also highlights the concern, respect and understanding of people. For managers to better mobilize the enthusiasm of teachers and students, to achieve the goal and the overall goal of organic unity, to promote the overall development of the school has an important guiding significance.

\section{Acknowledgements}

Fund Project: Project of Henan Key Universities for Scientific Research Project Name: "Human Capital Management Practice and Research in Newly-built Universities", Item Number: 17A880008. 


\section{References}

[1] Liu plus support. Human-based management in the management of colleges and universities [J]. Journal of Yichun University, 2011, 33 (1): 63-65.

[2] Zhou Feng. University Teachers' Incentives from the Perspective of Humanistic Management [J]. Literary World (Theoretical Edition), 2012, 11: 361,363.

[3] Zhang Mu Chu. Teacher-based management of multi-dimensional mechanism and its functions [J]. Teaching and Management, 2014, 22: 16-19.

[4] Zhao Liqing. On the development of innovative personnel the main countermeasures [J]. Monthly report of cadres and personnel, 2001, 8: 28-29.

[5] Tan Lin, Cui Jing. University Teachers' Incentives from the Perspective of Humanistic Management [J]. Economic Research Guide, 2011, 25: 154-155. 